Jurnal

Kardiologi Indonesia

J Kardiol Indones. 2012;33:190-5

ISSN 0I 26/3773

\title{
Referring STEMI Patient: When and Where?
}

\author{
Kurniawan Agung Yuwono
}

Graduated from Faculty of Medicine, University of Gadjah Mada, Yogyakarta
Management of STEMI patients consist of initial recognition and diagnosis, early routine medication, and reperfusion therapy. Primary $\mathrm{PCl}$ has been set as default strategy for STEMI reperfusion in $\mathrm{PCl}$-capable hospital. Unfortunately, only few STEMI patients can undergo primary $\mathrm{PCl}$ as reperfusion therapy, because the number of hospital with invasive capability is still low in many countries, including Indonesia. Because time is critical in reperfusion therapy, the emergency physicians in non- $\mathrm{PCl}$ capable hospital have to decide to hold or refer STEMI patients to a hospital with invasive capability. The reperfusion therapy options for STEMI patient presenting to a non- $\mathrm{PCl}$ capable hospital are fibrinolytic therapy, or refer to $\mathrm{PCl}$ capable hospital, or both (pharmacoinvasive strategy). This review tried to summarize the evidences as a consideration in choosing the best reperfusion strategy for STEMI patients presenting to non-PCl capable hospital.

(J Kardiol Indones. 2012;33:190-5)

Keywords: STEMI management, non-PCI capable hospital, reperfusion strategy, pharmacoinvasive strategy, referal 


\title{
Merujuk Pasien STEMI: Kapan dan Kemana?
}

\author{
Kurniawan Agung Yuwono
}

\begin{abstract}
Manajemen pasien yang datang ke UGD dengan STEMI meliputi pengenalan dini dan penegakan diagnosis, pengobatan rutin awal, dan terapi reperfusi.PCI primer telah ditetapkan sebagai strategi reperfusi yang dipilih bila pasien STEMI datang ke rumah sakit dengan fasilitas PCI.Namun hanya sedikit pasien STEMI yang dapat dilakukan terapi reperfusi definitif berupa PCI primer, karena jumlah rumah sakit dengan kemampuan reperfusi invasif masih sangat terbatas, termasuk di Indonesia.Karena waktu merupakan faktor penting dalam terapi reperfusi, dokter UGD di rumah sakit non-PCI harus memutuskan untuk menahan atau merujuk pasien ke rumah sakit dengan kemampuan reperfusi invasif. Maka pilihan terapi pasien STEMI yang datang ke rumah sakit tanpa fasilitas PCI adalah pemberian terapi fibrinolisis atau rujuk ke fasilitas PCI atau keduanya (strategi farmakoinvasif).Dalam tinjauan kepustakaan ini, kami mencoba merangkum bukti-bukti sebagai bahan pertimbangan dalam memilih strategi reperfusi yang terbaik untuk pasien STEMI yang datang ke rumah sakit non-PCI.
\end{abstract}

(J Kardiol Indones. 2012;33:190-5)

Kata kunci: Manajemen STEMI, rumah sakit non-PCI, strategi reperfusi, strategi farmakoinvasif, rujukan

\section{Pendahuluan}

Proses merujuk pasien STEMI yang datang ke rumah sakit non-PCI dimulai dari UGD, sehingga dokter UGD berperan penting dalam mendiagnosis, melakukan stratifikasi resiko dan merujuk pasien STEMI ke fasilitas yang memadai. PCI primer merupakan strategi reperfusi yang dipilih untuk pasien STEMI bila waktu memungkinkan. Pasien STEMI yang mendapat terapi reperfusi sesegera mungkin akan

\footnotetext{
Alamat Korespondensi:

dr. Kurniawan Agung Yuwono, Alumnus Fakultas Kedokteran UGM Yogyakarta, Tegalgondo RTOI/RWO I Wonosari, Klaten, Jawa Tengah, 57473.E-mail:bpk_agung@yahoo.co.uk,dr.agungyuwono@ gmail.com
}

mengalami penyembuhan ventrikel kiri yang semakin baik. ${ }^{1}$ Selain itu, waktu "door-to-ballon" yang kurang dari 90 menit dapat menurunkan angka kematian pada pasien STEMI. ${ }^{2,3}$ Oleh karena itu waktu adalah faktor yang sangat penting dalam penanganan pasien STEMI.

Apa yang harus dilakukan dokter UGD di rumah sakit non-PCI?

Menurut Guideline STEMI ACC/AHA (American College of Cardiology/American Heart Association) 2004, semua pasien STEMI harus menjalani evaluasi cepat untuk terapi reperfusi dan memiliki sebuah strategi reperfusi yang diimplementasikan dengan tepat setelah kontak dengan sistem medis (kelas I, LoE:A). ${ }^{4}$ 
Jurnal Kardiologi Indonesia

Banyak uji yang dilakukan di rumah sakit non-PCI yang membandingkan antara strategi thrombolisis on-site dan rujuk ke rumah sakit PCI, diantaranya meta-analisis oleh Dalbi et a ${ }^{5}$ dan De Luca et al. ${ }^{6}$ Hasil dari studi-studi tersebut menunjukkan luaran lebih baik dan signifikan pada strategi rujuk untuk PCI primer, dengan waktu dari rumah sakit awal sampai inflasi balon pertama di rumah sakit PCI dapat dicapai dalam $90-120$ menit.

Menurut guideline STEMI ACC/AHA update 2007, pasien STEMI yang datang ke rumah sakit yang mampu PCI harus diterapi dengan PCI primer dalam 90 menit dari kontak medis pertama (rekomendasi kelas: I, Level of Evidence:A). ${ }^{7}$ Sedangkan Guideline revaskularisasi miokardium ESC/EACTS 2010 (European Society of Cardiology/European Association for Cardio-Thoracic surgery) menyatakan PCI primer diindikasikan apabila PCI dapat dilakukan dalam $<120$ menit dari kontak medis pertama (kelas I, LoE:A). ${ }^{8}$ Dapat disimpulkan bahwa bila pasien datang ke rumah sakit non-PCI dan jarak dari rumah sakit perujuk sampai dilakukan prosedur PCI di fasilitas PCI $<90$ menit (atau < 120 menit), maka harus segera dirujuk ke fasilitas PCI untuk dilakukan PCI primer.

Namun jumlah fasilitas PCI di Indonesia masih sangat terbatas, sehingga sulit untuk menerapkan strategi PCI primer pada semua pasien STEMI. Menurut guideline STEMI ACC/AHA update 2007, bila pasien datang ke fasilitas non-PCI dan tidak dapat dirujuk ke fasilitas PCI dan dilakukan PCI dalam 90 menit pada kontak medis pertama, maka harus diterapi dengan fibrinolitik dalam 30 menit dari kedatangan ke rumah sakit ("door-to-needle" < 30 menit), kecuali terdapat kontra-indikasi fibrinolisis (kelas: I, LoE: B). ${ }^{7}$ Guideline revaskularisasi miokardium ESC/EACTS 2010 menyatakan bahwa fibrinolisis dapat diberikan oleh petugas pra-rumah sakit dengan peralatan yang memadai dan diberikan dalam dosis penuh (kelas: IIa, LoE: A). ${ }^{8}$

Kapankah pasien STEMI perlu dirujuk ke rumah sakit yang memiliki fasilitas PCI?

Menurut 2009 Focused Updates: ACC/AHA Guidelines, pasien resiko tinggi yang menerima terapi fibrinolitik sebagai terapi reperfusi primer pada fasilitas non-PCI, dapat dikirim sesegera mungkin ke fasilitas PCI, dimana PCI dapat dilakukan ketika dibutuhkan (PCI "rescue") atau sebagai strategi farmakoinvasif (PCI yang difasilitasi). Perhatian harus diberikan pada inisiasi regimen antithrombotik preparatorik (antikoagulan dan antiplatelet) sebelum dan selama transfer ke laboratorium katheterisasi (kelas IIa, LoE:B). ${ }^{9}$

\section{Siapa saja pasien STEMI resiko tinggi ?}

Menurut Guideline STEMI ACC/AHA update 2009, pasien STEMI resiko tinggi adalah pasien dengan $\geq 1$ poin dari salah satu kriteria di bawah ini:

1. Kriteria CARESS-in-AMI ${ }^{10}$ : elevasi ST ekstensif; onset baru LBBB; MI sebelumnya; kelas Killip $>2$; Fraksi ejeksi LV $\leq 42 \%$ untuk MI inferior; MI anterior dengan $\geq 2 \mathrm{~mm}$ elevasi ST pada $\geq 2$ lead.

2. Kriteria TRANSFER-AMI $1^{11}: \geq 2 \mathrm{~mm}$ elevasi ST pada 2 lead anterior atau $\geq 1 \mathrm{~mm}$ pada lead inferior; dengan minimal 1 kriteria: $\mathrm{sBP}<150 \mathrm{mmHg}$; heart rate $>150 \mathrm{bpm}$; kelas Killip II - III; $\geq$ $2 \mathrm{~mm}$ depresi ST pada lead anterior; atau $\geq 1 \mathrm{~mm}$ elevasi ST pada lead $\mathrm{V}_{4}$ sisi kanan mengindikasikan keterlibatan ventrikel kanan.

Sedangkan untuk pasien non-resiko tinggi yang menerima terapi fibrinolitik sebagai terapi reperfusi primer di fasilitas non-PCI, dapat juga dipertimbangkan untuk dirujuk sesegera mungkin ke fasilitas PCI (kelas IIb, LoE:C).

Sedangkan menurut Guideline revaskularisasi miokardium ESC/EACTS 2010, semua pasien STEMI yang mendapat terapi fibrinolisis harus segera dirujuk ke fasilitas PCI, agar dapat segera dilakukan PCI bila pasien mengalami kegagalan reperfusi. ${ }^{15}$ Bila fibrinolisis sukses (ketidaknyamanan/nyeri dada dan elevasi ST yang membaik), maka diindikasikan PCI rutin segera dalam 24 jam (kelas: I, LoE: A), sedangkan bila fibrinolisis gagal maka diindikasikan PCI "rescue" sesegera mungkin (kelas: IIa, LoE:A). ${ }^{15}$

\section{Bukti -bukti mengenai PCI rutin dini paska fibrinolisis}

PCI rutin dini paska fibrinolisi atau pada literature lain disebut strategi farmakoinvasif adalah sebuah strategi yang menggabungkan metode reperfusi fibrinolitik, kemudian pasien dirujuk segera untuk dilakukan PCI rutin. ${ }^{8}$ Alasan utama penggunaan PCI yang difasilitasi adalah terbatasnya akses ke RS yang mampu PCI.Reperfusi sementara dilakukan dengan thrombolisis kemudian dirujuk untuk mendapatkan reperfusi definitif dengan PCI diharapkan mampu menyelamatkan sebagian besar miokardium. 


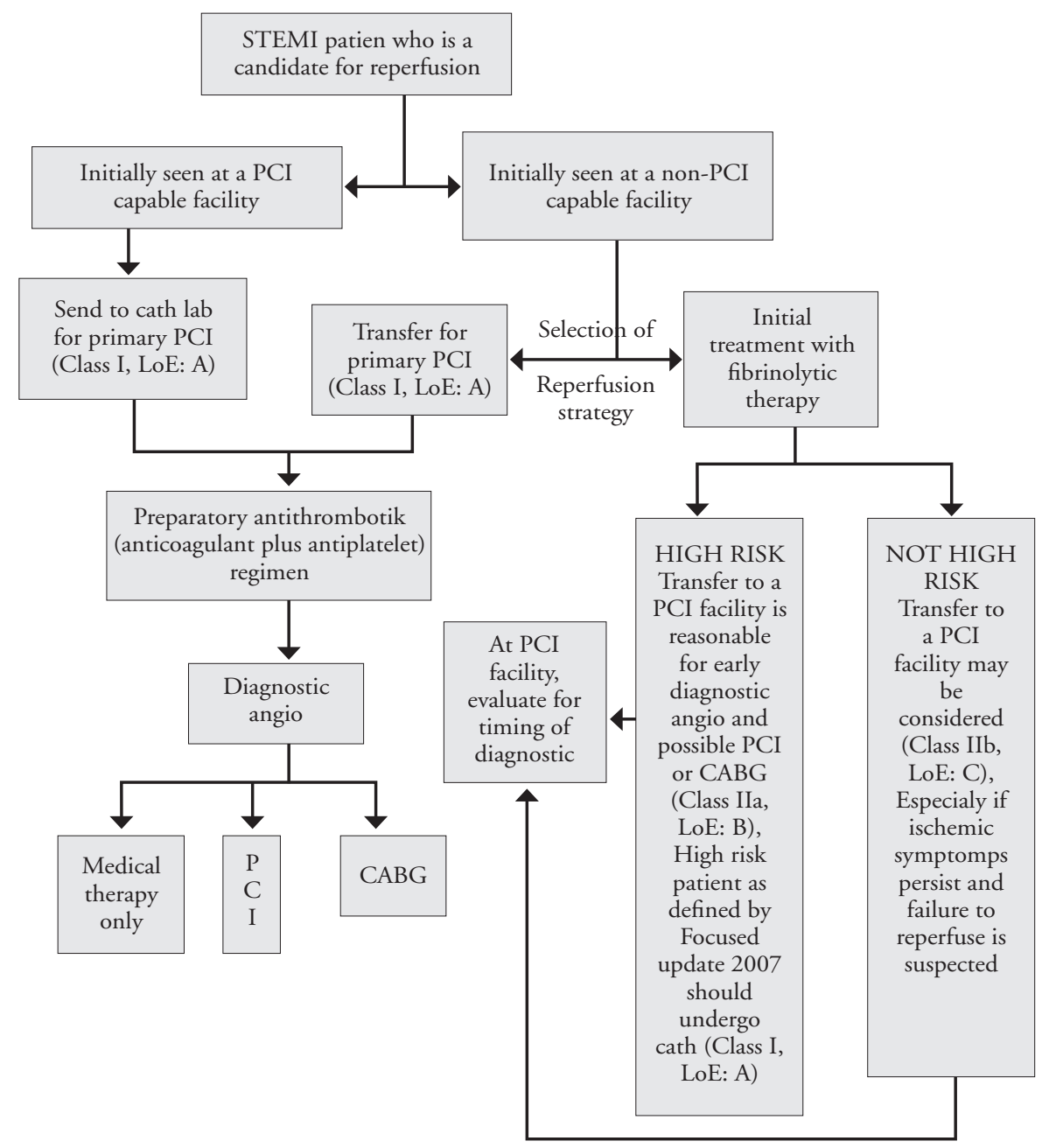

Gambar 1. Triase dan transfer untuk PCI (Sumber: Guideline STEMI ACC/AHA update 2009)9.

Wijeysurendera et al ${ }^{12}$ melakukan meta-analisis yang membandingkan 2 strategi konservatif yakni "rescue angioplasty" dan pengulangan thrombolisis paska kegagalan thrombolisis. Peningkatan luaran klinis terjadi pada grup yang diterapi dengan "rescue angioplasty", namunjuga disertai peningkatan potensial resiko, sehingga diperlukan strategi yang lebih baik dari rescue angioplasty.

Collet et al melakukan meta-analisis untuk membandingkan strategi invasif (PCI) rutin dini dengan strategi konservatif pada era balon dan era stent. ${ }^{13}$ Pada era balon, aspirin tidak segera diberikan pada semua pasien, thienopyridine belum tersedia, sedangkan pada era stent, aspirin dan thienopyrridine diberikan pada $>80 \%$ pasien dengan PCI rutin dini dan GP IIb/IIIa receptor antagonis diberikan pada $10-20 \%$ pasien tersebut.Studi-studi yang dilakukan pada era stent menunjukkan bahwa strategi PCI rutin dini memiliki luaran yang lebih baik. ${ }^{13} \mathrm{Hal}$ ini menunjukkan pentingnya pemberian obat antitrombus sebelum PCI untuk meningkatkan angka keberhasilan PCI.

Borgia et a ${ }^{14}$ melakukan sebuah meta-analisis terhadap 7 studi terkini yang membandingkan strategi invasif rutin dini vs. pendekatan konservatif ("rescue PCI”). Strategi invasive rutin dini berkaitan dengan pengurangan reinfarksi dan iskemi rekuren secara signifikan dibandingkan terapi konservatif, pada 30 hari dan follow up $6-12$ bulan.

Pada uji NORDISTEMI didapatkan hasil bahwa 87\% dari pasien STEMI yang datang ke rumah sakit non-PCI dan diacak pada strategi PCI rutin dini paska-fibrinolisis dapat mencapai "TIMI flow grade" 3 dan penundaan waktu dari fibrinolisis ke angiografi 
tidak mempengaruhi hasil luaran. ${ }^{15}$ Pada uji terkontrol acak GRACIA-2 (Grupo de Ana'lisis de la Cardiopatia Isque'mica Aguda), strategi PCI rutin dini paskafibrinolisis memiliki luaran perfusi miokardial yang lebih baik dari PCI primer (reperfusi penuh $21 \%$ vs $6 \%, p=0,003)$. Pada studi ini, perbedaan median waktu dari masuk rumah sakit sampai angiografi pada strategi PCI rutin dini dengan PCI primer sangat signifikan $(4,6$ jam vs 1 jam, $\mathrm{p}<0,001) .{ }^{16}$ bahwa :

Dari berbagai studi di atas dapat disimpulkan

1. Penundaan waktu "door-to-ballon" pada strategi PCI rutin paska-fibrinolisis tidak menjadi masalah sehingga metode ini efektif dan feasibel untuk dilakukan pada pasien yang tidak dapat dilakukan PCI primer.

2. Hal penting yang harus diperhatikan dalam strategi farmakoinvasif adalah pemberian regimen antithrombotik preparatorik (antikoagulan dan antiplatelet) yang adekuat, sebelum dan selama rujuk ke laboratorium katheterisasi untuk meningkatkan kesuksesan PCI.

Apakah harus merujuk ke rumah sakit PCI dengan kemampuan bedah jantung on-site?

PCI memiliki tingkat kegagalan yang rendah, ${ }^{17,18}$ namun bila mengalami keterlambatan untuk UCABG (urgent coronary artery bypass graft) akan membahayakan pasien. ${ }^{19}$ Studi - studi yang menyatakan bahwa PCI primer dapat dilakukan dengan aman di rumah sakit tanpa bedah jantung onsite diantaranya adalah Wharton et al, ${ }^{20}$ the Primary Angioplasty in Acute Myocardial Infarction-2 (PAMI).${ }^{17}$ Primary Angioplasty in Acute Myocardial Infarction at Hospital with No Surgery On-Site (The PAMI-No SOS), ${ }^{21}$ studi NCDR (national cardiovascular data registry). ${ }^{22}$

Guideline ACCF/AHA/SCAI mengenai PCI 2011, ${ }^{23}$ merekomendasikan:

1. PCI primer boleh dilakukan di rumah sakit tanpa bedah jantung on-site (rekomendasi kelas IIa, LoE: B)

2. PCI primer atau elektif tidak boleh dilakukan dirumah sakit tanpa bedah jantung on-site, bila tidak memiliki rencana yang terbukti untuk transport cepat ke ruang operasi bedah jantung di rumah sakit terdekat atau tanpa kemampuan support hemodinamik yang tepat untuk merujuk. (kelas III, LoE: C).

\section{Kesimpulan}

Waktu merupakan faktor penting dalam terapi pasien STEMI.PCI primer merupakan strategi yang dipilih bila pasien STEMI dapat mencapai waktu door-to-ballon < 90 menit atau $<120$ menit. Namun fasilitas PCI masih sangat terbatas, termasuk di Indonesia, sehingga sedikit rumah sakit non-PCI yang mampu memenuhi waktu door-to-ballon $<90$ menit (atau $<120$ menit) ketika merujuk.Strategi farmakoinvasif dipandang efektif sebagai strategi reperfusi untuk pasien STEMI yang datang ke rumah sakit non-PCI dengan resiko tinggi (menurut guideline ACC/AHA 2009) dan/atau jauh dari faslitas PCI (menurut guideline ESC/EACTS 2010).Ketersediaan kemampuan bedah jantung on-site tidak selalu menjadi keharusan, asalkan PCI dilakukan di faslitas PCI yang memenuhi syarat dan memiliki sistem rujukan efektif ke fasilitas bedah jantung bila dibutuhkan.

\section{Daftar pustaka}

1. Sheiban I., Fragaso G., Rosano G. M. C., Dharmadhikari A.,, Tzifos V., Pagnotta P., et al. Time Course and Determinants of Left Ventricular Function Recovery After Primary Angioplasty in Patients With Acute Myocardial Infarction. J Am Coll Cardiol 2001;38:464-71.

2. McNamara R. L., Wang Y., Herrin J., Curtis J. P., Bradley E. H., Magid D. J., et al. Effect of Door-to-Balloon Time on Mortality in Patients With ST-Segment Elevation Myocardial Infarction. Am Coll Cardiol 2006;47: 2180-6.

3. Brodie B. R., Hansen C., Stuckey T. D., Richter S., VerSteeg D. S., Gupta N., et al. Door-to-Balloon Time With Primary Percutaneous Coronary Intervention for Acute Myocardial Infarction Impacts Late Cardiac Mortality in High-Risk Patients and Patients Presenting Early After the Onset of Symptoms. J Am Coll Cardiol 2006;47: 289-95.

4. Antman EM, Anbe DT, Armstrong PW, Bates ER, Green LA, Hand M, et al. ACC/AHA guidelines for the management of patients with ST-elevation myocardial infarction: a report of the American College of Cardiology/American Heart Association Task Force on Practice Guidelines (Committee to Revise the 1999 Guidelines for the Management of Patients with Acute Myocardial Infarction). Circulation 2004;110:e82-e292.

5. Dalbi M., Bouzamondo A., Lechat P., Montalescot G. Transfer for Primary Angioplasty Versus Immediate Thrombolysis in Acute Myocardial Infarction: A Meta-Analysis. Circulation. 2003;108:1809-1814. 


\section{Yuwono KA: Merujuk Pasien STEMI: Kapan dan Kemana?}

6. De Luca G, Biondi-Zoccai G., Marino P. Transferring Patients With ST-Segment Elevation Myocardial Infarction for Mechanical Reperfusion: A Meta-Regression Analysis of Randomized Trials. Ann Emerg Med. 2008;52:665-676.

7. Antman EM, Hand M, Armstrong PW, et al. 2007 Focused Update of the ACC/AHA 2004 Guidelines for the Management of Patients With ST-Elevation Myocardial Infarction: a report of the American College of Cardiology/American Heart Association Task Force on Practice Guidelines: 2007 Writing Group to Review New Evidence and Update the ACC/AHA 2004 Guidelines for the Management of Patients With ST-Elevation Myocardial Infarction. J Am Coll Cardiol. 2008;51: 210-47.

8. Wijns W., Kolh P., Danchin N., Di Mario C., Falk V., Folliguet T., et al. Guidelines on myocardial revascularization The Task Force on Myocardial Revascularization of the European Society of Cardiology (ESC) and the European Association for Cardio-Thoracic Surgery (EACTS). European Heart Journal (2010) 31, 2501-2555.

9. Kushner FG, Hand M, Smith SC, King SB, Bates ER, Blankenship JC, et al. 2009 Focused Updates: ACC/AHA Guidelines for the Management of Patients With ST-Elevation Myocardial Infarction (Updating the 2004 Guideline and 2007 Focused Update) and ACC/AHA/SCAI Guidelines on Percutaneous Coronary Intervention (Updating the 2005 Guideline and 2007 Focused Update): A Report of the American College of Cardiology Foundation/American Heart Association Task Force on Practice Guidelines. Circulation. 2009;120:2271-2306

10. Di Mario C, Dudek D, Piscione F, et al. Immediate angioplasty versus standard therapy with rescue angioplasty after thrombolysis in the Combined Abciximab REteplase Stent Study in Acute Myocardial Infarction (CARESS-in-AMI): an open, prospective, randomised, multicentre trial. Lancet. 2008;371:559-68.

11. Cantor WJ, Fitchett D, Borgundvaag B, et al. Routine early angioplasty after fibrinolysis for acute myocardial infarction. $\mathrm{N}$ Engl J Med. 2009; 360:2705-18.

12. Wijeysurendera H. C., Vijayaraghavan R., Nallamothu B. K., Foody J. M., Krumholz H. M., Phillips C. O., et al. Rescue Angioplasty or Repeat Fibrinolysis After Failed Fibrinolytic Therapy for ST-Segment Myocardial Infarction : A Meta-Analysis of Randomized Trials. J Am Coll Cardiol 2007;49:422-30.

13. Collet J-P., Montalescot G., Le May M., Borentain M., Gershlick A. Percutaneous Coronary Intervention After Fibrinolysis: A Multiple Meta-Analyses Approach According to the Type of Strategy. J. Am. Coll. Cardiol. 2006;48;1326-1335.

14. Borgia F., Goodman S. G., Halvorsen S., Cantor W. J., Piscione F., Le May M. R., et al. Early routine percutaneous coronary intervention after fibrinolysis vs. standard therapy in ST-segment elevation myocardial infarction: a meta-analysis. European Heart Journal (2010) 31, 2156-2169.

15. Bohmer E, Hoffman P., Abdelnoor M., Arnesen H., Halvorsen S. Efficacy and Safety of Immediate Angioplasty Versus Ischemia-
Guided Management After Thrombolysis in Acute Myocardial Infarction in Areas With Very Long Transfer Distances: Results of the NORDISTEMI (NORwegian study on DIstrict treatment of ST-Elevation Myocardial Infarction). J Am Coll Cardiol 2010;55:102-10.

16. Fernandez-Aviles F., Alonso J., Pena G., Blanco J., Alonso-Briales J., Lopez-Mesa J., et al. Primary angioplasty vs. early routine postfibrinolysis angioplasty for acute myocardial infarction with STsegment elevation: the GRACIA-2 non-inferiority, randomized, controlled trial. European Heart Journal (2007) 28, 949-960

17. Sone G. W., Brodie B. R., Griffon J. J., Grines L., Boura J., O'neill W. W., et al. Role of Cardiac Surgery in the Hospital Phase Management of Patients Treated With Primary Angioplasty for Acute Myocardial Infarction. Am J Cardiol 2000;85:1292-1296.

18. Kernis S.J., Harjai K. J., Stone G. W., Grines L. L., Boura J. A., Yerkey M. W., et al. The Incidence, Predictors, and Outcomes of Early Reinfarction After Primary Angioplasty for Acute Myocardial Infarction. J Am Coll Cardiol 2003;42:1173-7.

19. Lotfi M., Mackie K., Dzavik V., Seidelin P. H. Impact of Delays to Cardiac Surgery After Failed Angioplasty and Stenting. J Am Coll Cardiol 2004; 43:337- 42.

20. Wharton T. P., McNamara N. S., Fedele F. A., Jacobs M. I., Gladstone A. R., Funk E. J. Primary Angioplasty for the Treatment of Acute Myocardial Infarction: Experience at Two Community Hospitals Without Cardiac Surgery. J Am Coll Cardiol 1999;33: 1257-65.

21. Wharton T. P., Grines L. L., Turco M. A., Johnston J. D., Souther J., Lew D. C. Primary Angioplasty in Acute Myocardial Infarction at Hospitals With No Surgery On-Site (The PAMINo SOS Study) Versus Transfer to Surgical Centers for Primary Angioplasty. J Am Coll Cardiol 2004; 43:1943-50

22. Kutcher M. A., Klein L. W., Ou F. S., Wharton T. P., Dehmer G. J., Singh M., et al. Percutaneous Coronary Interventions in Facilities Without Cardiac Surgery On Site: A Report From the National Cardiovascular Data Registry (NCDR). J. Am. Coll. Cardiol. 2009;54;16-24.

23. Levine G. N. Bates E. R., Blakenship J. C., Bailey S. R., Bittl J. A., Cercek B., et al. 2011 ACCF/AHA/SCAI Guideline for Percutaneous Coronary Intervention: A Report of the American College of Cardiology Foundation/American Heart Association Task Force on Practice Guidelines and the Society for Cardiovascular Angiography and Interventions. J. Am. Coll. Cardiol. 2011;58;e44-e122.

24. Smith SC Jr, Feldman TE, Hirshfeld JW Jr, Jacobs AK, Kern MJ, King SB III, et al. ACC/AHA/ SCAI 2005 guideline update for percutaneous coronary intervention: a report of the American College of Cardiology/American Heart Association Task Force on Practice Guidelines (ACC/AHA/SCAI Writing Committee to Update 2001 Guidelines for Percutaneous Coronary Intervention). Circulation 2006; 113:e166-e286. 